Transaction

(Received May 23, 1991)

\title{
SEPARATION OF AQUEOUS ORGANIC SOLVENTS THROUGH CROSSLINKED POLY(ACRYLATE-co-ACRYLIC ACID) MEMBRANES BY PERVAPORATION
}

\author{
Masaru Hoshi ${ }^{* 1}$, Takanori Saito*!, Akon Higuchi*', \\ and Tsutomu Nakagawa*2 \\ *1 Lintec Co., Ltd., Honcho, Itabashi-ku, Tokyo, 173 Japan \\ *2 Department of Industrial Chemistry, Meiji University, Higashi-mita, Tama-ku \\ Kawasaki, 214 Japan
}

\begin{abstract}
Pervaporation enrichment of chlorine containing organic hydrocarbons from dilute aqueous solution through poly (acrylate-co-acrylic acid) composite membranes with crosslinked structure was investigated. Five copolymers were synthesized and their membranes were prepared on a porous poly (propylene) sheet. These membranes have selectivity in favor of halogen containing hydrocarbons in addition to permeability, depending on side chains. The following acrylate monomers were used: butyl acrylate (BA), tert-butyl acrylate (tert-BA), lauryl methacrylate (LaMA), benzyl acrylate (BeA), cyclohexyl acrylate (CHA). Ratio of the acrylate monomer and acrylic acid was mostly 8.5/1.5 and 8.2/1.8. During the preparation of the membrane, crosslinking structure was introduced with $N, N, N^{*}$-tetra glycidyl metaxylenediamine (TGXDA). Pervaporation was carried out for aqueous solutions of 1,1,2-trichloroethane (TCE), trichloroethylene and tetrachloroethylene using the copolymer membranes. Separation factor 500 of TCE/water and flux $24 \mathrm{~g} / \mathrm{m}^{2} \cdot \mathrm{hr}$ were obtained at $25^{\circ} \mathrm{C}$, about $0.2 \mathrm{wt} \%$ aqueous feed composition for copoly (BA-acrylic acid) membrane.
\end{abstract}

\section{INTRODUCTION}

Considerable works have been carried out in academic and industrial laboratories to separate water/ethanol mixtures and other organic liquids/water. However, most of polymeric membranes have perm. selective for water except polydimethylsiloxane (1) and poly [1-(trimethylsilyl)-1-propyne] [2]. Recently, polyether-block-polyamides (PEBA) membranes have been found to exhibit exceptional selectivity for hy. drocarbons in pervaporation [3]. Pervaporation is an attractive process for the removal of dilute organic solvents particularly chlorinated solvents. Separation of solvents from their aqueous mixtures is fundamentally dependent on solubility selectivity and diffusivity selectivity, according to the solution-diffusion theory. In order to obtain polymeric membranes which exhibit both a high organic solvent selectivity and permeability, it appeares desirable to synthesize structures with high solubility to the organic solvent and with high diffusivity. The objective of the present study is to obtain polymeric membranes, composed of acrylate and acrylic acid monomers, which have both high selectivity and permeability for chlorinated organic solvents.

\section{THEORY}

The solution-diffusion theory was used in which a concentration difference of each penetrants between both sides of the membrane is a driving force for diffusion step. In the theory, 1) the concentration dif ference is derived from the chemical potential difference, and 2) the activity is a product of an activity coefficient and a concentration. From 1) and 2), the following general permeation equation is derived [4].

$$
\begin{aligned}
& \mathrm{J}_{\mathrm{i}}=\frac{\mathrm{D}_{\mathrm{i}}}{l}\left\{\mathrm{~K}_{\mathrm{i} 1} \mathrm{C}_{\mathrm{i} 1}^{\mathrm{s}}-\mathrm{K}_{\mathrm{i} 2} \mathrm{C}_{\mathrm{i} 2}^{\mathrm{s}} \exp \left[-\bar{V}_{\mathrm{i}}\left(\mathrm{P}_{\mathrm{i}}^{\mathrm{s}}-\mathrm{P}_{2}^{\mathrm{s}}\right) / \mathrm{RT}\right]\right\} \\
& \mathrm{J}_{\mathrm{i}}=\frac{\mathrm{P}_{\mathrm{i}}}{l}\left\{\mathrm{C}_{\mathrm{i} 1}^{\mathrm{s}}-\alpha_{\mathrm{i}} \mathrm{C}_{\mathrm{i} 2}^{\mathrm{s}} \exp \left[-\overline{\mathrm{V}}_{\mathrm{i}}\left(\mathrm{P}_{1}^{\mathrm{s}}-\mathrm{P}_{2}^{\mathrm{s}}\right) / \mathrm{RT}\right]\right\}
\end{aligned}
$$




$$
\alpha_{\mathrm{i}}=\frac{\mathrm{K}_{\mathrm{i} 1}}{\mathrm{~K}_{\mathrm{i} 2}}, \quad \mathrm{P}_{\mathrm{i}}=\mathrm{D}_{\mathrm{i}} \mathrm{K}_{\mathrm{i}}
$$

where $J_{i}$ is the flux for component $i$ in a unit time and a unit area through the membrane, $D_{i}$ is the diffusion coefficient for component $i$ throuth the membrane, $K_{i 1}$ and $\mathrm{K}_{\mathrm{i} 2}$ indicate solubility coefficients of up stream side and down stream side of the membrane, respectively, $\mathrm{C}_{\mathrm{i} 1}^{\mathrm{s}}$ and $\mathrm{C}_{\mathrm{i} 2}^{\mathrm{s}}$ indicate the concentration of component $i$ in the supplied solution and the solution of the permeated side, respectively, $\mathrm{P}_{1}^{\mathrm{s}}$ and $\mathrm{P}_{2}^{\mathrm{s}}$ are total pressures of both side of the membrane, $l$ is the thickness of the membrane and $\bar{V}_{i}$ is the partial molar volume of component $i$ in the membrane.

In our pervaporation experiment, the pressure of the permeated side of the membrane is near zero. Therefore, the Eq. 2 becomes a very simple form as follows:

$$
\mathrm{J}_{\mathrm{i}}=\frac{\mathrm{D}_{\mathrm{i}} \mathrm{K}_{\mathrm{i}}}{l} \mathrm{C}_{\mathrm{i} 1}^{\mathrm{s}} \text {, or } \mathrm{J}_{\mathrm{i}}=\frac{\mathrm{P}_{\mathrm{i}}}{l} \mathrm{C}_{\mathrm{i} 1}^{\mathrm{s}}
$$

However, the Eq. 3 might be used in very special case in which the diffusion coefficient is not dependent on the concentration and available so-called an active layer of the membrane which is a low pressure side of the membrane. Pervaporation effects, in the following section, are described in terms of the separation fac. tor of the preferentially permeating organic component versus permeating water, namely the concentration ratio as follows,

$$
\alpha_{\mathrm{j} / \mathrm{i}}=\frac{\mathrm{Y}_{\mathrm{j}} / \mathrm{Y}_{\mathrm{i}}}{\mathrm{X}_{\mathrm{j}} / \mathrm{X}_{\mathrm{i}}}
$$

where $Y_{i}$ and $Y_{j}$ refer to the concentration of components $i$ and $j$ in the permeate, while $X_{i}$ and $X_{j}$ are the concentrations of the same components in the feed solution. The total or partial flux, $\mathrm{kg} / \mathrm{m}^{2} \cdot \mathrm{hr}$, are used.

\section{EXPERIMENTAL}

\subsection{Preparation of Copolymers}

Poly (acrylate-co-acrylic acid) were prepared by solution polymerization with azobisisobutyronitrile as an initiator and a mixture of toluene and ethyl acetate as a solvent at $70^{\circ} \mathrm{C}$ for about $8 \mathrm{~h}$.

\subsection{Preparation of Membranes}

$N, \quad N, \quad N, \quad N$-tetraglycidilmetaxylenediamine (TGXDA) at the ratio $1 / 20$ of epoxy group/carboxylic group was added in a toluene solution containing $25 \%$ of copolymer. The solution was casted on a PET

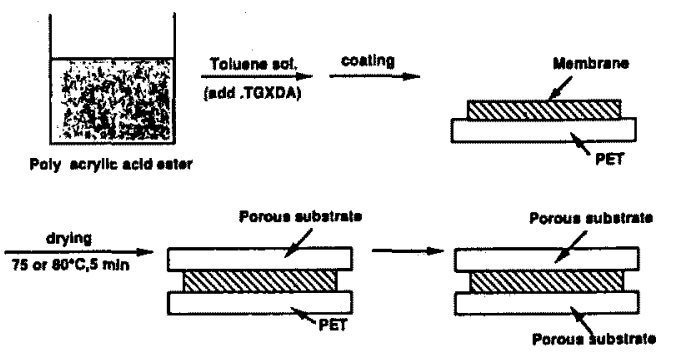

Fig. 1. Membrane preparation.

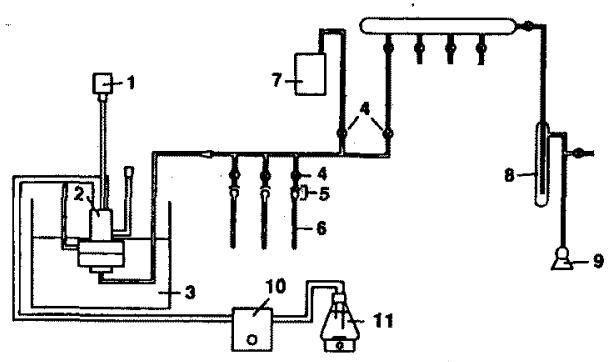

Fig. 2. Pervaporation apparatus.

1 stirring moter

2: pervaporation cell

3: constant temperature bath

4: Teflon needle valves

5: ground glass joints

6: cold traps for collecting sample

film at $25^{\circ} \mathrm{C}$ and then heated at $80^{\circ} \mathrm{C}$ for $5 \mathrm{~min}$ after drying. Thickness of the membranes was $60-70 \mu \mathrm{m}$. Then a porous poly (propylene) sheet, Duragard, was covered on the copolymer membrane and the PET film was displaced with Duragard. Thus, a sandwiched type composite membrane was prepared. Fig. 1 shows the membrane preparation method of this type.

\subsection{Pervaporation}

Schematic diagram of pervaporation apparatus is shown in Fig. 2. Pervaporation was usually made at $25{ }^{\circ} \mathrm{C}$. Concentration of halogenated organic solvents and water was measured by a gas chromatography.

\section{RESULTS AND DISCUSSION}

Chemical structure of poly (acrylate-co-acrylic acid) and crosslinking agent are summarized in Table 1. Effect of the side chain structure on pervaporation performance of 1,1,2-trichloroethane (TCE)/water 
Table 1 Chemical Structure of Monomers and Crosslinking Agent

\begin{tabular}{|c|c|c|c|c|}
\hline \multirow{2}{*}{ monomer } & \multirow[b]{2}{*}{$\mathrm{R}_{1}$} & \multirow[b]{2}{*}{$\mathrm{R}_{2}$} & \multicolumn{2}{|c|}{ Mole fraction ${ }^{11}$} \\
\hline & & & $\mathrm{m}$ & $\mathrm{n}$ \\
\hline Butyl acrylate (BA) & $-\mathrm{H}$ & $-\mathrm{C}_{1} \mathrm{H}_{9}$ & 0.853 & 0.147 \\
\hline tert-Butyl acrylate (tert-BA) & $-\mathrm{H}$ & $-\mathrm{C}\left(\mathrm{CH}_{3}\right)_{3}$ & 0.853 & 0.147 \\
\hline Lauryl methacrylate (LaMA) & $-\mathrm{CH}_{3}$ & $-\mathrm{C}_{12} \mathrm{H}_{25}$ & 0.745 & 0.255 \\
\hline Benzyl acrylate $(\mathrm{BeA})$ & $-\mathrm{H}$ & $-\mathrm{CH}_{2}-\mathrm{O}$ & 0.821 & 0.179 \\
\hline Cyclohexyl acrylate (CHA) & $-\mathrm{H}$ & - (A) & 0.829 & 0.171 \\
\hline
\end{tabular}

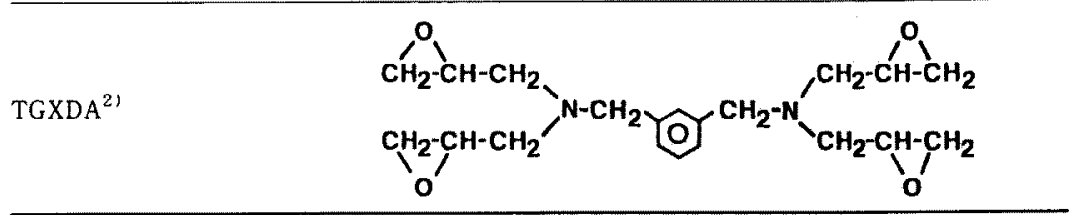

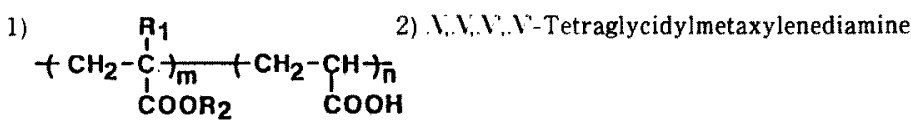

Table 2 Pervaporation of TCE-Water Mixture through Poly (acrylic acid ester-co-acrylic acid) membranes at $25^{\circ} \mathrm{C}$

\begin{tabular}{|l|c|c|c|c|r|}
\hline \multicolumn{1}{|c|}{ Membrane } & TCE in feed $(\mathrm{wt} \%)$ & $\alpha_{\mathrm{PV}}(\mathrm{TCE} / \mathrm{Water})$ & $\begin{array}{c}\text { Flux } \\
10^{2} \cdot\left(\mathrm{kg} / \mathrm{m}^{2} \cdot \mathrm{hr}\right)\end{array}$ & Thickness $(\mu \mathrm{m})$ & $\mathrm{Tg}\left({ }^{\circ} \mathrm{C}\right)$ \\
\hline BA-AA & 0.170 & 485 & 2.40 & 65.6 & -32.9 \\
\hline LaMA-AA & 0.193 & 2264 & 1.37 & 47.6 & -50.8 \\
\hline Iert-BA-AA & 0.182 & 8.20 & 0.508 & 74.0 & 38.1 \\
\hline CHA-AA & 0.186 & 31.0 & 0.364 & 59.6 & 11.3 \\
\hline BeA-AA & 0.201 & 108 & 0.638 & 79.2 & 4.9 \\
\hline
\end{tabular}

Table 3 Sorption and Pervaporation Data for Poly (acrylic acid ester-co-acrylic acid) membranes at $25^{\circ} \mathrm{C}$

\begin{tabular}{|l|c|c|c|c|c|c|}
\hline \multirow{2}{*}{ Membrane } & \multicolumn{3}{|c|}{ Sorption data } & \multicolumn{3}{c|}{ Pervaporation data } \\
\cline { 2 - 7 } & $\begin{array}{c}\text { TCE in feed } \\
(\mathrm{wt} \%)\end{array}$ & $\begin{array}{c}\text { TCE in membrane } \\
(\mathrm{wt} \%)\end{array}$ & $\alpha_{\mathrm{S}}(\mathrm{TCE} / \mathrm{Water})$ & $\begin{array}{c}\text { TCE in feed } \\
(\mathrm{wt} \%)\end{array}$ & $\alpha_{\mathrm{PV}}(\mathrm{TCE} / \mathrm{W}$ ater $)$ & $\begin{array}{c}\text { Flux } \\
10^{2} \cdot\left(\mathrm{kg} / \mathrm{m}^{2} \cdot \mathrm{hr}\right)\end{array}$ \\
\hline BA-AA & 0.200 & 68.83 & 1103 & 0.170 & 485 & 2.40 \\
\hline LaMA-AA & 0.200 & 76.83 & 1654 & 0.193 & 2264 & 1.37 \\
\hline lert-BA-AA & 0.175 & 34.29 & 297 & 0.182 & 8.20 & 0.508 \\
\hline CHA-AA & 0.225 & 34.47 & 233 & 0.186 & 31.0 & 0.364 \\
\hline BeA-AA & 0.225 & 40.42 & 301 & 0.201 & 108 & 0.638 \\
\hline
\end{tabular}

mixture through poly (acrylate-co-acrylic acid) at 25 ${ }^{\circ} \mathrm{C}$ is summarized in Table 2. As can be seen, separa. tion factor is the highest for poly (LaMA-AA) in this series, because of the better solubility selectivity, based on the affinity of TCE to the long hydrocarbon side chain of the polymer. This is supported by the results of sorption data shown in Table 3 . However, the highest flux is obtained for poly (BA-AA) membranes. This result should be attributed to the lower diffusion coefficient, because that BA has the smallest 
Table 4 Sorption and Pevaporation Data for BA-AA (TGXDA 0.05) membrane at $25^{\circ} \mathrm{C}$

\begin{tabular}{|l|c|c|c|c|c|c|}
\hline \multirow{2}{*}{ Solvent } & \multicolumn{3}{|c|}{ Sorption } & \multicolumn{3}{c|}{ Pervaporation } \\
\cline { 2 - 7 } & $\begin{array}{c}\text { Feed concentration } \\
(w t \% \text { of solv. })\end{array}$ & $\begin{array}{c}\text { Solv. in membrane } \\
(\mathrm{wt} \%)\end{array}$ & $\begin{array}{c}\alpha_{\mathrm{S}} \\
(\text { Solv } / \mathrm{W} \text { ater })\end{array}$ & $\begin{array}{c}\text { Feed concentration } \\
(\mathrm{wt} \% \text { of solv. })\end{array}$ & $\begin{array}{c}\alpha_{\mathrm{pv}} \\
(\text { Solv. } / \text { Water })\end{array}$ & $\begin{array}{c}\text { Flux } \\
10^{2} \cdot\left(\mathrm{kg} / \mathrm{m}^{2} \cdot \mathrm{hr}\right)\end{array}$ \\
\hline $1,1,2$-Trichloroethane & 0.200 & 68.83 & 1103 & 0.202 & 708 & 3.63 \\
\hline Trichloroethylene & 0.0521 & 51.94 & 2075 & 0.0529 & 804 & 2.13 \\
\hline Tetrachlororthylene & 0.00719 & 21.18 & 3737 & 0.00652 & 905 & 1.51 \\
\hline
\end{tabular}

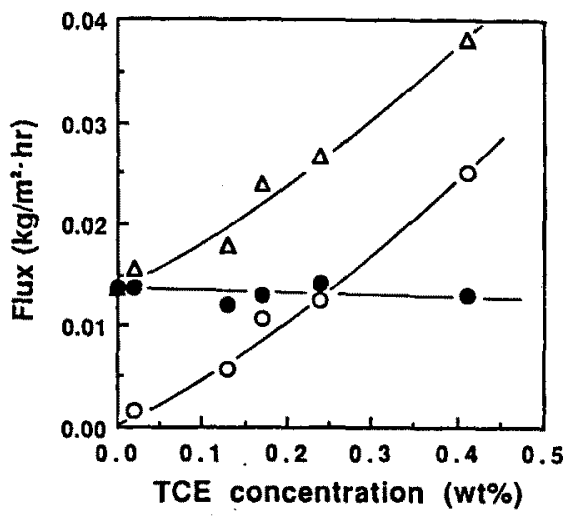

Fig. 3. Effect of feed composition on partial and overall flux of TCE-water mixture through BA-AA (TGXDA 0.05) membrane at $25^{\circ} \mathrm{C}:(\triangle)$ overall. (O) TCE, water.

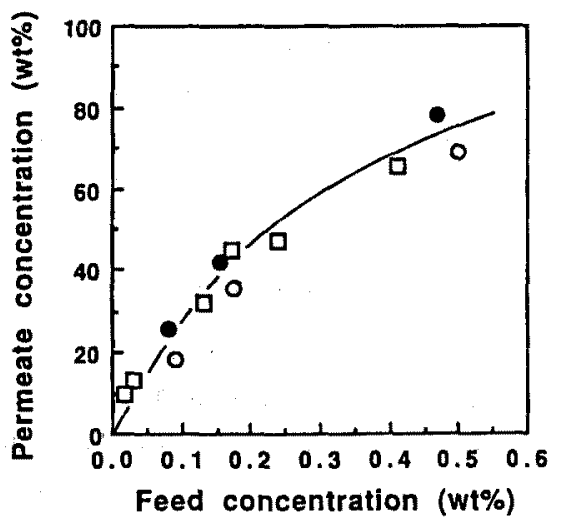

Fig. 4. Effect of feed composition on the separation of organic solvent-water mixtures through BA-AA (TGXDA $0.05)$ membrane at $25^{\circ} \mathrm{C}$ : (O) chloroform, (O) EDC, ( $\square$ ) TCE.

side chain in this series and is considered to have the lowest filling effect in the intersegmental spaces. Glass transition temperature, $T_{g}$, of these copolymers was measured. However, the coincidence of the order

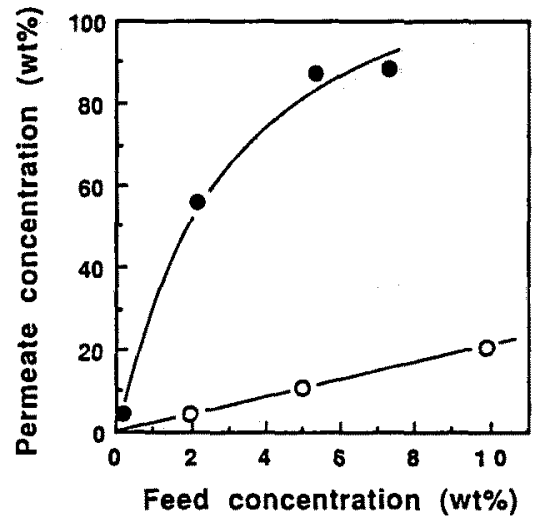

Fig. 5. Effect of feed composition on the separation of organic solvent-water mixtures through BA-AA (TGXDA $0.05)$ membrane at $25^{\circ} \mathrm{C}$ : (O) ethyl acetate. $(O)$ ethanol.

of $\mathrm{T}_{g}$ 's with the order of their permeation rates was not obtained. The copolymer membrane with a relatively high $\mathrm{T}_{\mathrm{g}}$ shows the relatively low permeation rate in this series. Poly (BA-AA) membrane is found to be totally the excellent membrane. Comparing the separation factor by pervaporation with that of sorption, the former is lower than the latter. This suggests that diffusivity selectivity is less than 1. Diffusion coefficient of water in the poly (acrylate-co-acrylic acid) membranes is considered to be higher than that of TCE, considering its molecular size. This phenomena are found in Table 4 which shows pervapora. tion data of $\mathrm{TCE} /$ water, trichloroethylene/water and tetrachloroethylene/water. Poly (BA-AA) membrane has high separation factor as well as good permeation rate. If very thin membranes such as $1-2 \mu \mathrm{m}$ will be obtained, higher permeation rate is expected.

Effect of feed composition on partial and overall permeation rate of TCE/water mixture through the poly (BA-AA) is shown in Fig. 3. The permeation rate increased with increasing the feed concentration of 


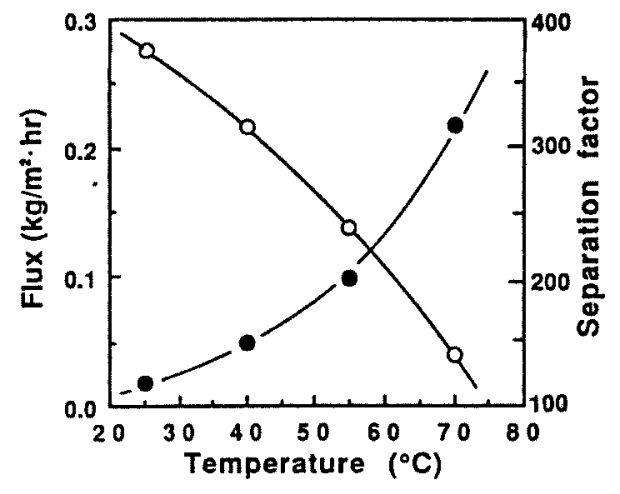

Fig. 6. Temperature dependence of flux and separation factor of BA-AA (TGXDA 0.05) membrane. TCE concen. tranion $0.2 \mathrm{wt} \%$ : (O) separation factor.

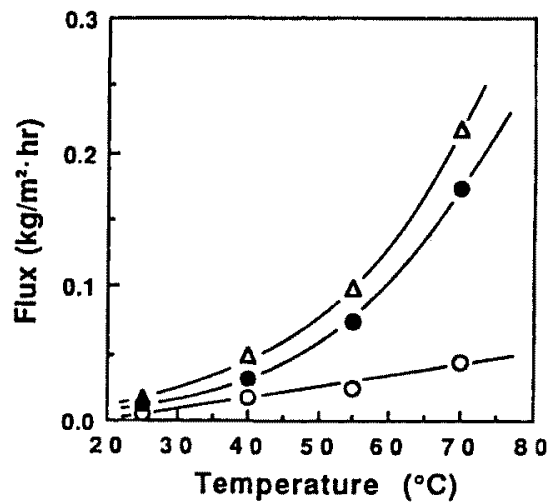

Fig. 7. Temperature dependence of partial and overall flux of BA-AA (TGXDA 0.05) membrane. TCE concentration 0.2 wt\%: $(\Delta)$ overall, $(O)$ TCE, $(O)$ water.

Table 5 Effect of Substrate for Separation of TCE-Water Mixture through BA-AA (TGXDA 0.05) membranes at $25^{\circ} \mathrm{C}$

\begin{tabular}{|l|c|c|c|c|}
\hline \multicolumn{1}{|c|}{ Substrate } & $\begin{array}{c}\text { Feed concentration } \\
(\mathrm{wt} \% \text { of TCE) }\end{array}$ & $\begin{array}{c}\alpha_{\mathrm{PV}} \\
(\mathrm{TCE} / \mathrm{Water})\end{array}$ & $\begin{array}{c}\text { Flux } \\
10^{2} \cdot\left(\mathrm{kg} / \mathrm{m}^{2} \cdot \mathrm{hr}\right)\end{array}$ & $\begin{array}{c}\text { Thickness }(\mu \mathrm{m}) \\
\text { (BA-AA Layer) }\end{array}$ \\
\hline Duragard & 0.202 & 708 & 3.63 & 61.8 \\
\hline Fluoropore & 0.206 & 773 & 2.93 & 48.8 \\
\hline Cellulose acetate & 0.206 & 122 & 3.78 & 70.0 \\
\hline
\end{tabular}

TCE. It seems that both permeation rates of TCE and water obey the Eq. 3. The permeation rate of water slightly decreased with increasing TCE concentration. As far as the data are concerned, in Fig. 3, no effect of TCE concentration on the water permeation rate for the poly (BA-AA) membrane was found. Effect of feed composition on the separation of other organic solvents/water mixtures through poly (BA-AA) membrane is shown in Figs. 4 and 5.

Temperature dependence of permeation rates and separation factor of $\mathrm{TCE} /$ water mixture through poly (BA-AA) membrane are shown in Fig. 6. The separation factor decreased remarkably with the increasing of the temperature. The reason is quite simple as shown in Fig. 7 . In a high temperature region, molecular motion of the side chain of the polymer becomes easier and this is effective for the diffusion of small molecules, water; namely, the diffusivity selectivity is very small than 1 .

Effect of kind of supported porous sheet on the pervaporation performance was considered. In the case that hydrophobic porous polymeric sheets such as poly (propylene) and polytetrafluoroethylene, Fluoropore, were used, the higher separation factors were obtained as shown in Table 5, although without poly (acrylate-co-acrylic acid) membranes, no separation were obtained. Therefore, somehow concentration polarization might occur on the surface of the feed side of the membrane.

\section{CONCLUSION}

Pervaporation enrichment of chlorinated organic solvents such as trichloroethane (TCE) from dilute aqueous solution through poly (butyl acrylate-coacrylic acid) membrane with crosslinked structure was found to be available. The poly (lauryl metha. crylate-co-acrylic acid) membrane with rather long hydrocarbon groups as side chaines showed the highest solubility selectivity but a little bit lower diffusivity selectivity. Poly (butyl acrylate-co-acrylic acid) membrane with crosslinked structure showed both high selectivity and permeation rate in this series. The permeation rate of TCE increased with increas. ing the feed concentration and thus separation factor 
also increased. No effect of TCE solved in the membrane on the permeation rate of water was found. The porous supporting polymeric sheet also showed the great influence on the separation of $\mathrm{TCE} /$ water mix. ture.

\section{REFERENCES}

1. For example, $Y$. Nagase, $Y$. Takamura and $K$. Sugimoto, International Conference on Mem. branes and Membrane Processes, Aug. 19-24, 1991. Chicago, pp. 331

2. For example, H. H. Nijhuis, M. H. Mulder and C. A. Smolders, International Conference on Mem. branes and Membrane Processes, Aug. 19-24, 1991, Chicago, pp. 319

3. K. W. Boddeker and G. Bengston, J. Membrane Sci., 53, 143 (1990)

4. C. H. Lee, J. Ippl. Polım. Sci.. 19, 83 (1975) 